\title{
CORPO, ESTÉTICA E IDEOLOGIA: UM DIÁLOGO COM A IDEIA DE BELEZA NATURAL
}

\author{
BODY, ESTHETICS AND IDEOLOGY: A DIALOGUE WITH THE DEFINITION OF \\ NATURAL BEAUTY
}
CUERPO, ESTÉTICA E IDEOLOGÍA: UN DIÁLOGO CON LA IDEA DE BELLEZA NATURAL

Tadeu João Ribeiro Baptista*, Sílvia Rosa da Silva Zanolla*

Palavras-chave:

Corpo humano.

Estética.

Beleza.

Teoria Crítica
Resumo: A ciência tem criticado a padronização e alienação de beleza corporal alcançada pelo consumismo com exercícios compulsivos, dietas rigorosas, etc. 0 objetivo deste ensaio é discutir a perspectiva dialética da beleza natural em Adorno, considerando sua concepção crítica de beleza corporal. O texto fundamenta-se na ideia adorniana de beleza natural. Em seguida, dialoga com a ideia social de beleza corporal contemporânea. Finalmente, sinaliza, pelo universo cultural, possibilidades de reconhecimento das diferenças em contraponto à padronização humana. Considera a beleza natural de cada pessoa como forma de resistência à lógica da sociedade administrada esteticamente, em termos objetivos e subjetivos.

Abstract: Science has criticized standardization and alienation of body beauty caused by consumerism with compulsive exercise, strict diets, among others. This essay discusses the dialectical perspective of natural beauty in Adorno, considering his critical conception of body beauty. The text is based on Adorno's idea of natural beauty. Then, it dialogues with the social idea of contemporary body beauty. Finally, in the cultural universe, it signals possibilities of recognizing differences in contrast to human standardization. It considers each person's natural beauty as a way of resisting the logic of an aesthetically managed society in objective and subjective terms.
Palabras clave: Cuerpo humano. Estética.

Belleza.

Teoria Crítica.
Resumen: La ciencia ha criticado la estandarización y la alienación de la belleza corporal alcanzada por el consumismo con ejercicios compulsivos, dietas estrictas, entre otros. El propósito de este ensayo es discutir la perspectiva dialéctica de la belleza natural en Adorno, considerando su concepción crítica de belleza corporal. El texto se fundamenta en la idea de Adorno de belleza natural. Luego, dialoga con la idea social de belleza corporal contemporánea. Por último, señala el universo cultural, las posibilidades de reconocimiento a las diferencias en contraste con la estandarización humana. Considera la belleza natural de cada persona como una forma de resistencia a la lógica de la sociedad estéticamente administrada, en términos objetivos y subjetivos.
Universidade Federal de Goiás. Goiânia, GO, Brasil. E-mail: tadeujrbaptista@yahoo.com.br

Recebido em: 26-01-2016 Aprovado em: 02-05-2016 (c) (1) (8) Licence 


\section{INTRODUÇÃO}

A questão corporal e estética tem sido preocupação na literatura científica, sendo foco de discussão de autores no campo da Educação Física (HASSE, 2009; GODOI, 2011; PAIXÃO; LOPES, 2014). Os padrões referentes ao corpo estão voltados para a busca de um modelo "perfeito", o qual apresenta como características centrais a juventude, a magreza aliada à musculatura bem delineada, estatura mediana para alta, pele branca, cabelos lisos e soltos. A estas características ideologicamente tem-se atribuído o valor da beleza e, portanto, da estética. Apesar do interesse de pesquisas que estudam a relação entre o corpo e a cultura ter crescido no Brasil, percebe-se carência de produções em perspectivas críticas.

Segundo Eagleton (1995), a estética nasce com um discurso sobre o corpo e tem como referência a construção de uma beleza com tendência a sublimar ou se sobrepor a todos os sentidos. Na contemporaneidade, o corpo considerado belo agrega a noção de saúde atendendo características de bem-estar físico definido pela Organização Mundial de Saúde (OMS), como capacidade cardiovascular, força relacionada à definição muscular, flexibilidade e composição corporal magra. Assim, é possível pensar o corpo como lócus de existência da força de trabalho, adquirindo características de mercadoria (BAPTISTA, 2013).

Este corpo belo e saudável encontra a sua defesa, sobretudo, entre pesquisadores das ciências biológicas, pois estes compreendem a necessidade de se manter certos padrões corporais voltados para a saúde, considerando faixas etárias diferentes. Identificam-se estes trabalhos no Brasil e no exterior (BRANCO et al., 2015; KUSNIERZ; POSPIECH; ROGOWSKA, 2015; COLEDAM et al., 2016).

Não obstante, como toda mercadoria, o valor atribuído constitui fetiche, porquanto adquire características místicas e fantasmagóricas, efeitos de sua ideologização. Como mercadoria, o corpo esconde o fato de seu valor ser definido pela quantidade de trabalho humano necessário para a sua constituição, por isso, o corpo é carcaça do tempo, sobretudo, quando se trata de pensar o corpo do trabalhador na perspectiva marxiana (BAPTISTA, 2013). A ideia de ser o corpo uma mercadoria não é consenso entre pesquisadores desse campo, embora alguns entendam o corpo como capital humano e material, ensejando problematizar essa temática na perspectiva crítica (GOLDENBERG, 2010).

A discussão sobre o corpo no capitalismo apresenta várias possibilidades, inclusive a relação com o modelo demonstrado pela indústria cultural. Este conceito emerge em 1947, elaborado por Adorno e Horkheimer (1985), para explicar a resistência e atualização do sistema capitalista através da reestruturação do universo cultural pós-Segunda Guerra Mundial. Nesse sentido, apresenta o universo da diversão e do entretenimento como extensão do trabalho e das relações produtivas em um contexto em que a exploração humana encontra sua razão no investimento ao consumo exacerbado (ZANOLLA, 2007). Essa indústria contribui para disseminar um modelo social que pode colaborar para a população se convencer sobre a necessidade de manter capacidades e habilidades adequadas ao capitalismo atual. Afinal,

[...] a "indústria cultural" mostra a regressão do esclarecimento à ideologia, que encontra no cinema e no rádio sua expressão mais influente. 0 esclarecimento consiste aí, sobretudo, no cálculo da eficácia e na técnica de produção e difusão. Em conformidade com seu verdadeiro conteúdo, a ideologia se esgota na idolatria daquilo que existe e do poder pelo qual a técnica é controlada. No tratamento desta 
contradição, a indústria cultural é levada mais a sério do que gostaria (ADORNO; HORKHEIMER, 1985, p. 16).

A indústria cultural é um importante elemento da ideologia capitalista. Tem como foco estabelecer o processo de controle técnico de diferentes componentes sociais, entre eles o corpo, identificado como importante dimensão da vida humana em suas características individuais diversificadas.

Assim sendo, precisa-se discutir o respeito às características corporais, considerando diferenças, riscos de preconceito e toda compreensão social ampla de beleza e saúde. Por isso, entendemos a necessidade de pensar a beleza como sinônimo de experiência estética no sentido cultural e formativo, articulando algumas produções apresentadas por autores da Teoria Crítica frankfurtiana. Adorno faz reflexões significativas sobre a visão ampla da estética a partir dessa teoria. Este importante intelectual alemão do século XX era sociólogo, musicista e filósofo de formação, tinha uma visão profunda da relação entre artes em geral, estética, psicologia e sociedade. Entre suas atividades estava a crítica à música, literatura, cinema e TV, permeada por uma reflexão densa sobre conceitos de estética e seus nexos sociais que levam à alienação através da cultura.

Uma de suas obras mais significativas publicada após a sua morte foi o livro Teoria Estética (1970). Neste texto inacabado, entre as discussões estabelecidas, uma se destaca por ter se debruçado sobre a noção de "beleza natural".

Pensando em travar um debate sobre a estética do corpo e a noção de beleza natural, em Adorno este texto objetiva apresentar uma noção de beleza corporal na perspectiva crítica frankfurtiana.

Destarte, este trabalho apresenta alguns pressupostos sobre a noção de beleza natural na obra Teoria Estética de Adorno, bem como propõe debater a noção de beleza natural e a possibilidade de se considerar em meio à regência da indústria cultural uma crítica consistente à ideia de beleza corporal.

\section{DIÁLOGOS CRÍTICOS COM A DEFINIÇÃO DE BELEZA NATURAL NA OBRA TEORIA ESTÉTICA DE T. W. ADORNO}

Theodor W. Adorno (1903-1969) foi um dos principais autores do Instituto de Pesquisas Sociais, mais conhecido como Escola de Frankfurt, junto com Max Horkheimer, Herbert Marcuse, Walter Benjamin e, mais recentemente, Jurgen Habermas. Adorno era famoso por sua crítica às artes em geral, especialmente à música, pela análise filosófica das motivações sociopsicológicas que levam à alienação no aspecto material e humano (JAY, 1974; MATOS, 2005).

Entre suas obras, destaca-se uma, na qual Adorno faz uma análise sobre a questão da beleza e da estética: Teoria Estética (1970). Esse texto foi organizado por Gretel Adorno, após a sua morte, em 1969, sendo lançado na Alemanha (IBID, 1970). O livro configura um monobloco, sem divisões específicas ${ }^{1}$. Contudo, a divisão e o desenvolvimento dos parágrafos apresentam algumas temáticas específicas. Uma delas refere-se à forma como 0 autor trabalha a questão da beleza natural, um tema cientificamente instigante para tratar e dialogar com a noção de beleza corporal².

1 Neste caso remetemos à edição de 1970 (Edições 70).

2 Devido à densidade dessa discussão, iremos nos debruçar sobre as reflexões que, a nosso ver, mais ajudam a pensar a questão do corpo apresentadas pela obra Teoria Estética, de Adorno. 
Uma primeira reflexão diz respeito a compreender o que é estética para Adorno:

A definição de estética como teoria do belo é pouco frutuosa porque o caráter formal do conceito de beleza deriva do conteúdo global de estético. [...] A ideia de beleza evoca algo de essencial na arte sem que, no entanto, o exprima imediatamente. Se não se afirmasse dos artefactos, de maneiras muito modificadas, que eles são belos, o interesse por eles seria incompreensível e cego, e ninguém [...], teria a oportunidade de sair do reino dos fins práticos, o da autoconservação e do princípio do prazer [...] (1970, p.65).

Preliminarmente, Adorno (1970), remete a uma relação coincidente entre a estética com o sentido contraditório da noção de beleza, na dialética entre essência e aparência. Se não fosse esta tensão presente naquilo que se pode denominar de beleza, a negatividade do belo seria vencida. Pode-se identificar que a beleza não é imediata, mas se dá no processo das mediações estabelecidas culturalmente no contexto individual e, simultaneamente, nas determinações das relações sociais mais amplas. A "negatividade" da beleza está em que: "De certo modo, o belo surgiu do feio mais do que ao contrário" (ADORNO, 1970, p.65).

$O$ belo se configura também na tensão entre 0 uno e o diverso, sendo um processo de "[...] emancipação da angústia perante a totalidade esmagadora e a opacidade da natureza" (ADORNO, 1970, p.66). Assim, a estética adquire certa condição de irresistibilidade, ainda que a beleza tenha como seu contraponto a fealdade e o horror presentes inclusive na morte (um fim em si mesmo pela padronização que é autodestrutiva). Apesar disso, "[...] o caráter formal da beleza, com toda a ambivalência do triunfo, transforma-se em expressão, na qual o aspecto ameaçador da dominação da natureza se une com a nostalgia do que é dominado e se ilumina com tal dominação" (ADORNO, 1970, p.67).

Todavia, para dialogar com a questão da beleza e da natureza, precisa-se refletir a priori sobre a compreensão do conceito de natureza na perspectiva sócio-histórica. Não obstante, considerando o senso comum, a natureza diz respeito à flora, à fauna, aos minerais, enquanto elementos constitutivos do planeta. Por outro lado, a natureza também diz respeito às construções humanas. Para Freud (1973), a natureza humana agrega contradições entre necessidade de sobrevivência e possibilidades de inserção social. O homem se socializa na luta contra a natureza instintual individualizada por comportamentos competitivos e agressivos socialmente. Entretanto, a natureza não é apenas fator orgânico constitutivo, considerada pura, intocada, de diferentes formas; direta ou indiretamente, esta é transformada pela mão humana na perspectiva social, histórica e materialista (MARX; ENGELS, 1998). Por isso, em alguns momentos, Adorno (1970) chega a falar em uma segunda natureza, posto que, sendo humanamente manipulada, esta se transforma em algo diferente do anterior, um novo elemento natural.

Adorno se fundamenta em vários autores, sobretudo Marx, para elaborar o conceito de natureza na perspectiva sócio-histórica. A história é antes de tudo da própria natureza a partir de sua relação com o humano, ou seja, a natureza passa a existir quando faz sentido e se torna objeto de contraponto para a consciência humana (MARX; ENGELS, 1998). Relacionada à consciência, a natureza se caracteriza como um objeto já tocado pelo trabalho. Ao transformar a natureza os humanos transformam-se a si mesmos. Contudo, considerar o processo de interação entre homem e natureza significa conceber a relação da natureza com ela própria, pois o ser humano é natural ${ }^{3}$ (MARX, 2010). 
Dizer do humano como ser natural é pensar sua dimensão histórica e social, tendo esta em si a própria dimensão estética. Assim, retorna-se o debate fundamental sobre natureza estética e orgânica presente no corpo humano como ponto importante para pensar a capacidade cognitiva e física para construção da obra de arte e da cultura. Na perspectiva adorniana, a "[...] obra de arte, inteiramente qese ${ }^{4}$, produto humano, representa 0 que seria juse $^{5}$, não simplesmente coisa em si. A obra de arte tanto se identifica com o sujeito como outrora ela própria deveria ser natureza" (ADORNO, 1970, p.78; Grifos gregos do autor).

Uma obra se articula em relação com a beleza da arte e a natureza em sua dimensão histórica e contraditória: ser social. Segundo Adorno (1970, p.80):

A maneira como o conceito de belo natural se transforma historicamente manifestase do modo mais impressionante no facto de, só no decurso do séc. XIX, nele se ter incorporado um domínio que, enquanto campo de artefactos, devia antes de mais estar com ele em oposição: 0 da paisagem cultural. Obras históricas, muitas vezes em relação com o seu meio ambiente geográfico [...], são percebidas como belas.

O aspecto histórico da beleza natural pode ser identificado dentro de uma perspectiva dinâmica e contraditória. Da noção de apreciação configurada em torno do ambiente natural, muito frequente no romantismo e, por outro lado, em tempos de racionalidade instrumental pode-se identificar processos ideológicos em meio à publicidade e às marcas da sociedade mercadológica (ADORNO, 1970). A compreensão de beleza ainda resvala em meio à racionalização, independente da força da formalização da percepção. Nesse contexto, é possível compreender que a "[...] racionalização não é ainda racional, a universalidade da mediação não se transformou em vida activa; isso fornece aos vestígios de imediatidade antiga, sempre questionável e ultrapassada, um momento de justiça correctiva" (ADORNO, 1970, p.80).

Assim, a beleza se configura em meio à tensão entre sujeito e objeto, percepção e racionalidade, objetivo e subjetivo, particular e universal, entre formas de intervenção humana e componentes criados pela própria natureza, embora pensar esta criação implique considerar uma natureza humanamente tocada. Assim, nos

[...] períodos em que a natureza se contrapõe com sua omnipotência aos homens, não há nenhum lugar para 0 belo natural [...]. 0 belo natural, pretensamente a-histórico, possui seu núcleo histórico; isso legitima-o tanto como relativiza o seu conteúdo. Onde a natureza não era realmente dominada, a imagem da sua nãodominação suscitava o terror. Daí, a predilecção durante muito tempo surpreendente pelas ordenações simétricas da natureza (ADORNO, 1970, p.81. Grifo nosso).

Isso diz respeito à noção de historicidade do objeto enquanto elemento munido de beleza natural. Por um lado, a beleza natural se configura pela dimensão a-histórica, considerando que, em muitos casos, o belo o é eternamente. Por outro lado, cada objeto, natural ou não, parece estar imbuído de uma beleza que transcende o tempo e o espaço, possuindo uma identidade. Como dito pelo próprio Adorno, a desconsideração pela historicidade da beleza natural também se configura como ideológica, compreendendo-se a estética definida pelos padrões de produção de cada tempo.

Devido a isso,

[...] o progresso civilizacional facilmente engana os homens sobre o modo como eles continuam sem proteção. A felicidade encontrada na natureza estava ligada

4 [Qesei] - Por "determinação voluntária" ver nota do tradutor da obra de Adorno (1970).

5 [Jusei] - Por "natureza" ver nota do tradutor da obra de Adorno (1970). 
à concepção do sujeito como um ser-para-si e virtualmente infinito em si; ele projecta-se assim na natureza e sente-se próximo dela enquanto separado; a sua impotência na sociedade petrificada em segunda natureza transforma-se no motor da fuga para a natureza supostamente original (ADORNO, 1970, p.81).

A beleza natural acompanha as mediações societárias históricas da realidade em contradição. Esta perspectiva de construção de um ser-para-si permite um diálogo com Hegel (2003), que traz para a beleza natural, enquanto objeto, a forma de fazer o sujeito constituir integralmente sua consciência. Destarte, a relação entre o humano e esta segunda natureza permite à pessoa uma tentativa de ligação consigo, embora, dentro da lógica capitalista, esta articulação de integralidade não seja possível (MARX, 2010; MARX, 2011).

A relação lógica do ser com o belo natural perpassa a ideia da natureza como um fenômeno.

O modo de articulação do belo natural e do belo artístico revela-se na experiência que àquele se aplica. Ela refere-se à natureza unicamente enquanto fenómeno, não enquanto material de trabalho e reprodução da vida, muito menos ainda enquanto substrato da ciência. Tal como a experiência artística, a experiência estética da natureza é uma experiência de imagens. A natureza enquanto belo fenomenal não é percebida como objeto de acção. A renúncia aos fins da autoconservação, enfática na arte, realiza-se igualmente na experiência estética da natureza (ADORNO, 1970, p.81).

Analisar a natureza como um fenômeno, a partir da ótica de Adorno, é reconhecer a beleza natural dada na dimensão fenomênica. Exige identificar a essência e suas extensões históricas, apreendendo a síntese das múltiplas determinações que as constituem. Ademais, deve-se destacar a ideia de experiência estética caracterizada pela experimentação da imagem. Afinal, a imagem, em certo sentido, possibilita interpretar o objeto de maneira imediata. Socialmente, a razão instrumental tende a se apropriar do belo apenas em sua condição aparencial e a-histórica.

A racionalidade, tornada estética, a disposição imanente dos materiais, que se the acomodam para a obra, resulta em algo de semelhante ao momento natural no comportamento estético. As tendências quase racionais de arte, com a renúncia crítica aos tópoí, a organização plena das obras singulares em si levada ao extremo, os produtos da subjectivação aproximam as obras em si de um natural dependente de um sujeito omnipotente, jamais através da imitação; "a origem é o objetivo", com mais razão para a arte (ADORNO, 1970, p.82. Grifo do autor).

A racionalidade acomodada na obra de arte da sociedade capitalista é a coisificação humana como construção subjetiva dada pela não completude do ser, mas, ao contrário, dada por sua fragmentação subjetiva em nome da pseudoindividualidade. Promessa de individuação traída pelo individualismo. Emerge daí a dialética da beleza natural:

O facto de a experiência do belo natural, pelo menos segundo a sua consciência subjectiva, se manter aquém da dominação da natureza como se ela fosse originalmente dada, parafraseia sua força e sua fraqueza. A sua força, porque ela relembra o estado de não-dominação, que provavelmente nunca existiu; a sua fraqueza, porque ela se dissolve precisamente assim no amorfo de onde se elevou 0 génio que só podia caber em sorte àquela ideia de liberdade realizada num estado de não dominação. [...] O belo natural é o mito transposto para a imaginação e, talvez por isso, liquidado (ADORNO, 1970, p.82).

6 Nota do tradutor da obra (ADORNO, 1970). 
No contexto entre a força e a fraqueza do belo natural, entre as condições subjetivas e as objetivas, a possibilidade de combater a dominação da natureza em suas contradições constitui aspecto sobremaneira formativo. Possibilita a consciência de um conflito vital para a constituição da dialética na relação entre sujeito e objeto. Destarte, considerar o fenômeno do belo natural é pôr em questão a perspectiva de uma beleza padronizada e coisificada, amorfa, no sentido de não possuir identidade, sendo ele, portanto, dinâmico e diferenciado.

Enfim, deve-se ter clareza: 0 "[...] belo natural define-se antes pela indeterminação, imprecisão do objeto não menos que do conceito. Enquanto indeterminado, em antítese com as determinações, o belo natural é indefinível; [...]" (ADORNO, 1970, p.89). Definir o belo natural consiste em lidar com a indeterminação do objeto. Este autor afirma que não há algo na natureza que seja mais belo do que outro, porquanto:

O belo natural é o vestígio do não-idêntico nas coisas, sob o sortilégio da identidade universal. Enquanto ele agir, nenhum não-idêntico lá existe positivamente. Por isso, o belo natural permanece tão disperso e incerto, assim com o que ele promete ultrapassa todo o intra-humano (ADORNO, 1970, p.90).

A compreensão de uma beleza natural como componente do não idêntico, de dispersão e incerteza, permite discutir e refletir um contexto específico da sociedade atual, a ideia da existência de um modelo de corpo que seja considerado belo a partir da relação de ser idêntico, sempre igual, um modelo padronizado por uma estética totalitária que tem características específicas já mencionadas, como pretende sugerir a indústria cultural, que "procura dar a tudo um ar de homogeneidade, embora, a semelhança perfeita é a diferença absoluta. [...] A indústria cultural realizou maldosamente o homem como ser genérico" (ADORNO; HORKHEIMER, 1985, p. 136).

A questão de uma estética do corpo vinculada com a noção de beleza natural em Adorno (1970) é o que abordaremos a seguir. Uma vez que esta reflexão é mais ampla e perpassa a relação entre a natureza e a obra de arte, analisaremos os fundamentos para compreender questões ideológicas referentes ao corpo.

\section{BELEZA NATURAL E IDEOLOGIA: REFLEXÃO PARA SE PENSAR A ESTÉTICA DO CORPO}

No Brasil, autores importantes dialogam com a Teoria Crítica frankfurtiana para tratar a questão do corpo, sobretudo, Albino e Vaz (2008) e Vaz (1999). Embora o debate seja insuficiente e careça investir em perspectivas críticas, estas pesquisas contribuem e convergem para análises considerando a indústria cultural, e o controle corporal por meio de processos diversificados adotados pela sociedade capitalista envolvendo produtos como esportes, cirurgias plásticas, suplementos e alimentos, cosméticos, entre outros (SILVA, 2001; LIMA; BATISTA; LARA JUNIOR, 2013).

Entretanto, a literatura da Educação ou da Educação Física não discute consistentemente a ideia da beleza natural do corpo, apesar de toda a crítica feita ao modelo padronizado de corpo apresentado pela indústria cultural. Optamos por apresentar este debate como uma possibilidade de se contrapor à ideia de uma beleza padronizada, com base em modelos predeterminados e estandardizados como mencionados anteriormente.

Um dos primeiros elementos para se pensar a estética do corpo procede dos modelos da arte apresentada pelos antigos. Afirma Adorno (1970, p.25): 
Nenhuma estátua grega, na sua nudez, era uma pin-up. Não se poderia explicar de outro modo a simpatia dos modernos pelo passado longínquo, e também pelo exótico: os artistas apelam para a abstracção dos objectos naturais com algo de desejável. [...] Semelhante prazer pode intensificar-se até o inebriamento; mas, mais uma vez, o conceito mesquinho de deleite não lhe basta, o qual seria antes apto para desabituar do prazer. De resto, é curioso que uma estética, que sempre insistiu na sensibilidade subjectiva como fundamento do Belo, jamais tenha analisado seriamente esta sensação.

Iniciou-se o debate pelo modelo do deleite, do prazer promovido pela estatuaria grega devido à relação entre subjetividade e objetividade (necessidade e sociabilidade) construída desde aquele período. Atribui-se, entre as obras de arte gregas, a noção de beleza e de estética à relação a-histórica que fundamenta certa funcionalidade e objetividade. A beleza, 0 deleite e o prazer presentes na estética passam por um crivo subjetivo, uma triagem na condição de compreender individualmente e coletivamente o que é ou não belo (ADORNO, 1970). O critério objetivo da noção de beleza estabelecido por meio da lógica social definida pela racionalidade instrumental parece subsumir a própria subjetividade. A objetivação da imagem subjetivada, leva à indiferenciação e à padronização, ao preconceito na instituição obrigatória de modelos aceitos ou pré-digeridos culturalmente como sendo uma condição social. Provavelmente, esta subsunção da subjetividade invertida justifica, em dada medida, os modelos apresentados na literatura sobre o padrão de corpo belo estabelecido pela indústria cultural.

$\mathrm{Na}$ conjuntura da beleza em contraste com a obra de arte pode-se refletir sobre 0 processo de reconhecimento da ideia de sensualidade através de padrões estabelecidos com o corpo, porquanto a sensualidade se dá, aparentemente, pela beleza objetivada. Esta, por sua vez, pode apresentar certa dissonância na tentativa de reconciliação, contradições entre desejo e necessidade (erotismo e perversão, pornografia e amor), renúncia e satisfação. Por essa lógica do corpo, "[...] a dissonância aproxima-se muitíssimo de seu contrário: a reconciliação; torna-se inflexível contra a aparência do humano, da ideologia da inumanidade, e inclina-se para o lado da consciência reificada" (ADORNO, 1970, p.27).

A consciência da lógica coisificada e a ideologia da inumanidade poderia trazer a preocupação de se constituir corpos que ficassem fora dos padrões efetivos da estética valorizada pelo capitalismo, ou seja, a ideia dos corpos considerados ideologicamente belos possuírem padrões de imagem que devem ser alcançados de modo ideal, da ordem do mercado, adquiridos, considerando o fato de o corpo ser uma mercadoria (BAPTISTA, 2013) ou uma forma de capital (GOLDENBERG, 2010), pois fatores materiais e culturais definem a imagem corporal relativa ao valor de beleza.

Este dado, inclusive, considera o emblema referente a alguns grupos de mulheres preocupadas com a imagem corporal, considerando as influências de fatores como a família, a escola e a mídia (KEYVANARA; HAGHIGHATIAN; KAVZADEH, 2013). Isso remete a Adorno, para quem de tão "[...] flagrante, se tornou a desproporção entre a cultura estabelecida e 0 estado das forças produtivas: socialmente, o que é em si consequente aparece como uma factura não obrigatória para o futuro [...]" (ADORNO, 1970, p. 51). Este estado de desproporção evidencia-se na construção de um modelo corporal aparentemente voltado para a construção do hedonismo que concilia desde a arte profana ao corpo sagrado; da estética ao trabalho.

Dialeticamente, o hedonismo estético, ainda presente na obra de arte - e por que não dizer no próprio corpo? - possui um lado do prazer contrastando com um lado sombrio. Afinal, 
[...] o hedonismo estético, o qual sobreviveu às catástrofes, censura como perversão ao postulado do sombrio, [...] que os momentos mais tenebrosos da arte devem preparar algo como o prazer, reduz-se a que a arte e uma consciência recta dela só podem encontrar a sua felicidade na capacidade de resistência. (ADORNO, 1970, p.54).

A ideia do hedonismo presente na tensão entre o prazer e o lado sombrio constitui possibilidade de resistência face ao conflito que questiona a estandardização corporal. Uma saída contra o hedonismo está no prazer que pode ser identificado na capacidade de resistência a modelos de beleza corporal. Talvez essa saída esteja na ideia de uma beleza natural e original, mesmo tocada pelos diferentes produtos e estratégias usadas socialmente, podem ser garantidos por aquilo que Benjamin (2011) denomina "aura" da obra de arte. Comparando o corpo à obra de arte, pode-se imaginá-lo permeado por uma identidade histórica, cuja constituição parte de contradições entre ser sujeito e ser objeto simultaneamente. Pois, para Adorno:

O fenómeno da aura descrito por Benjamin com uma negação nostálgica perverteuse onde ele se aplica e deste modo simula; onde produtos, que após a produção e reprodução se opõem ao hic et nunc, se baseiam na aparência de um tal hic et nunc, como o filme comercial. Isso, evidentemente, prejudica também o produto individual, desde que este conserve a aura, ordene o particular e se apresse a socorrer a ideologia, a qual se mimoseia com o bem individuado que existiria ainda no mundo administrado (ADORNO,1970, p. 59. Grifos do autor).

A aura é uma "categoria" que possibilita a mediação entre sujeito e objeto, técnica e criação na reflexão sobre a estética do corpo. Considerado como obra de arte, o corpo individuado deve ser social. Isso difere da condição de individualidade, em que prevalece 0 sujeito egoico e narcísico (ADORNO, 2000). Contrariamente, a individuação caracterizar-se-ia pela autonomia, capacidade de responder por seus atos na perspectiva kantiana da maioridade que visa à emancipação (ADORNO, 2000). Dizer de um corpo individuado é dizer de certa dissonância por sua beleza natural, constituída ao longo da vida, garantidas, dentro do possível, das suas características originais.

A dissonância pode apresentar estranhamento aos olhos socialmente constituídos por certa fealdade, pois a própria ideia de beleza e feiura é social, histórica e ideológica. Atendem a um sistema administrador do universo cultural que visa satisfazer-se pelo lucro. Destarte, tão

[...] inteiramente dinâmica é a categoria do feio como igualmente necessária é a sua contraparte, a categoria do belo. Ambas escarnecem de uma fixação definitória tal como é imaginada por qualquer estética, cujas normas, mesmo indirectamente, se orientam por essas categorias (ADORNO, 1970, p.60-61).

A beleza e a fealdade carecem de uma definição, embora precise-se considerar a beleza do corpo a partir de suas características inatas. Parece ser uma forma de contraposição à lógica de uma sociedade regida pela ordem do mercado. Segundo Vaz (1999), se todas as modificações corporais possíveis - pelas cirurgias, dietas, treinamentos e cosméticos - representam demanda por controle da natureza, garantia da lógica da beleza natural provavelmente dissonante, pode-se romper com esta racionalidade, porquanto,

[...] a dominação visível da natureza, onde a natureza vira para os homens a fachada do não-dominado. Aquela indignação insere-se, pois, na ideologia da dominação. Semelhante fealdade desapareceria se um dia a relação dos homens com a natureza se expurgasse do carácter repressivo, que perpetua a opressão 
do homem, e não o inverso. [...] O que aparece como feio é, antes de mais, o que está historicamente envelhecido, o que é rejeitado pela arte a caminho de sua autonomia, o que é em si mesmo mediatizado (ADORNO, 1970, p.61).

Essa passagem destaca dois férteis elementos para a discussão sobre o corpo. 0 primeiro diz respeito à relação de dominação da natureza e seu caráter repressivo. 0 segundo, à ideia de que o feio está historicamente vinculado ao que se considera envelhecido (ADORNO, 1970, p. 61).

Refletir sobre a lógica do corpo estandardizado é considerar a ideia de domínio da natureza enquanto caráter repressivo ao processo de elaboração da consciência. É compreender que o corpo modificado atende certa racionalidade voltada para a estética da mercadoria em meio às diferentes relações sociais, sejam elas no trabalho ou em outros espaços em que comparece mais efetivamente o mundo afetivo e sexual. Estabelece-se 0 fetiche para esta mercadoria, subvertendo sujeito ao valor de objetificação. Este valor se dá na lógica da estimulação, que, no limite, reprime o processo de conscientização da realidade pelo sujeito, portanto, em certo sentido, converte-se em alienação. Reprimir a consciência para manter o controle da sociedade administrada significa estimular a regressão e a infantilização do sujeito fazendo emergir sua porção lasciva (referente às necessidades primárias) a serviço dos processos da indústria cultural (ADORNO; HORKEIMER, 1985).

Isso remete ideologicamente, à ideia do feio enquanto algo historicamente envelhecido. Eis outra contradição a ser analisada ainda que brevemente do ponto de vista do corpo. A beleza, de modo repressivo e imediato, apresenta uma concepção ao mesmo tempo sedutora porque aceita, fetichizante e a-histórica. Enquanto o belo, na perspectiva dialética (contemplando suas contradições), parece ser indefinidamente determinado, em qualquer situação ou contexto histórico. Contudo, aquilo que sai da lógica do belo de certo período histórico acaba por se tornar feio. A maneira como a forma se desenvolve socialmente definirá as características aceitas e que são modificadas com o passar do tempo.

Provavelmente, nesta sociedade a idade e a velhice estão sempre na contramão da beleza, pois características como rugas, cabelos brancos e aumento de peso se contrapõem à lógica da produtividade capitalista. Por outro lado, a própria velhice é absorvida pela indústria como mercadoria, tornando-se potencial consumidora que objetiva o rejuvenescimento. A velhice como mercadoria só tem sentido na sua própria negação enquanto produto a ser descartado.

Segundo Marx (2010), a ideia de beleza é também apropriada pela burguesia. Ao trabalhador, a beleza é expropriada, com isso, as suas características corporais são associadas à feiura, dada a sua condição de oprimido. "O oprimido, que deseja a revolução, é vulgar, segundo as normas da bela vida da sociedade feia, desfigurado pelo ressentimento, carrega todos os estigmas da degradação do fardo do trabalho servil, sobretudo corporal" (ADORNO, 1970, p.63).

Este contexto revela a coisificação humana que medeia as relações entre seres humanos e suas verdadeiras experiências. Por isso, penetrante com a estrela do cinema, segundo a qual ele seria, de facto, finalmente pré-fabricado: mesmo onde a experiência de algo de natural se dá como a de um indivíduo integral, com se ela estivesse protegida da administração, tem a 
tendência para mistificar. O belo natural, na época da sua total mediatização, transforma-se na sua caricatura; o respeito da natureza incita antes, perante a sua contemplação, a exercer um ascetismo enquanto o belo natural estiver impregnado das marcas da mercadoria (ADORNO, 1970, p.83-84).

Significa isso que o belo fugidio contempla a compulsão por uma beleza inexistente, ideal e inalcançável, fruto da mistificação que alimenta o consumismo permeado pela administração da cultura industrial. Enfim, a partir dessas reflexões, compreendemos a necessidade de se romper com a lógica da mercadoria presente na ideia de beleza corporal, tão difundida na atualidade.

\section{CONSIDERAÇÕES FINAIS}

Adorno (1970) compreende a beleza natural como uma característica reveladora de contradições a partir da noção de estética, dissonante e parte da natureza orgânica e social, relacionada à cultura como obra de arte. Esta ideia parece ser fértil para se refletir a respeito da ideologia da beleza pela imagem do corpo humano.

Se entendermos o corpo humano como construção material na relação dialética entre natureza, sociedade e cultura, há de se compreender as características ideológicas legitimadas como sendo belas. Por outro lado as características naturais de cada corpo devem ser consideradas como fundamentais para se romper com a lógica da sociedade administrada. Respeitar as características sociais e individuais é, no limite, considerar a aura estética de cada corpo, sua identidade, contradições e história; construto identitário a não ser idealizado, repetido, mimetizado, banalizado. É possibilitar emergir processos formativos contra o preconceito e a padronização humana. Enfim, se na lógica da indústria cultural a estandardização é um componente de controle social, resistir à ideia de uma beleza comum e generalizada é uma forma de tentar garantir, através de uma consciência estética, a individuação e a emancipação do ser humano.

\section{REFERÊNCIAS}

ADORNO, Theodor W. Educação e Emancipação. 2. ed. Rio de Janeiro: Paz e Terra, 2000.

ADORNO, Theodor W. Teoria estética. Lisboa: Edições 70, 1970.

ADORNO, Theodor W.; HORKHEIMER, Max. Dialética do esclarecimento: fragmentos filosóficos. Rio de Janeiro: Jorge Zahar, 1985.

ALBINO, Beatriz S.; VAZ, Alexandre F. O corpo e as técnicas para o embelezamento feminino: esquemas da Indústria Cultural na Revista Boa Forma. Movimento, v. 14, n. 1, p.199-223; jan./abr. 2008.

BAPTISTA, Tadeu J. R. A educação do corpo na sociedade do capital. Curitiba: Appris, 2013.

BENJAMIN, Walter. Magia e Técnica, arte e política: ensaios sobre literatura história da cultura. 7. ed.. 11. reimp. São Paulo: Brasiliense, 2011. (Obras Escolhidas, v. 1).

BRANCO, Jeronimo Costa et al. Benefícios físicos e redução de sintomas depressivos em idosos: resultados do Programa Nacional de Caminhada Português. Ciência \& Saúde Coletiva, v. 20, n. 3, p. 789-795, 2015.

COLEDAM, Diogo Henrique Constantino et al. Fatores associados à aptidão cardiorrespiratória de escolares. Revista Brasileira de Medicina do Esporte, v. 22, n. 1, p. 21-26, 2016. 
EAGLETON, Terry. A ideologia da estética. Rio de Janeiro: Jorge Zahar, 1993.

FREUD, Sigmund. O mal estar na cultura. In: FREUD, Sigmund. Obras completas. Madrid: Biblioteca Nueva, 1973.

GODOI, Marcos R. Corpos femininos volumosos e estética: discursos contra-hegemônicos sobre beleza em blogs na internet. Movimento, v. 17, n. 3, p.153-173, jul./set de 2011.

GOLDENBERG, Mirian. O corpo como capital: gênero, casamento e envelhecimento na cultura brasileira. Redige: Revista de Design, Inovação e Gestão Estratégica. v. 1, n.1, p.192-200, 2010.

HASSE, Manuela. Branca, limpa e alinhada: a ressignificação da natureza no processo de transformação do corpo feminino (1938-1972). In: GRANDO, B. S. (Org.). Corpo, educação e cultura: práticas sociais e maneiras de ser. ljuí: Ed. Unijuí, 2009. p.53-73.

HEGEL, Georg W. F. Fenomenologia do espírito. 2. ed. rev. Petrópolis: Bragança Paulista: Vozes/ USF, 2003.

JAY, Martin. La imaginación dialéctica: historia de la Escuela de Frankfurt y el Instituto de Investigación Social. Madrid: Taurus, 1973.

KEYVANARA, Mahmoud; HAGHIGHATIAN, Mansur; KAVZADEH, Adeleh. Social factors influencing women's body image in Isfahan City. Journal of Applied Sociology, v. 48, n. 4, p.11-14, winter 2013.

KUSNIERZ, Cezary; POSPIECH, Dariusz; ROGOWSKA, Aleksandra M. Hierarchy of physical education goals as an expression of educational priorities among Polish teachers. Revista brasileira de Cineantropometria e desempenho humano, v. 17, n. 5, p. 592-600, 2015.

LIMA, Aluísio F. de; BATISTA, Karina de A.; LARA JUNIOR, Nadir. A ideologia do corpo feminino perfeito: questões com o real. Psicologia em Estudo, v. 18, n. 1, p.49-59, jan./mar. 2013.

MARX, Karl. Manuscritos Econômico-Filosóficos. 4. reimp. São Paulo: Boitempo, 2010.

MARX, Karl. 0 Capital: crítica da economia política. 29. ed. Rio de Janeiro: Civilização Brasileira, 2011. Livro 1, v. 1.

MARX, Karl; ENGELS, Friedrich. A Ideologia alemã. São Paulo: Martins Fontes, 1998.

MATOS, Olgária C. F. A Escola de Frankfurt: luzes e sombras do iluminismo. 2. ed. São Paulo: Moderna, 2005.

PAIXÃO, Jairo A. da; LOPES, Maria de F. Alterações corporais como fenômeno estético e identitário entre universitárias. Saúde em Debate, v. 38, n. 101, p.267-276, abr.jjun., 2014.

SILVA, Ana M. O corpo do mundo: algumas reflexões acerca da expectativa de corpo atual. In: GRANDO, José C. (Org.). A (des)construção do corpo. Blumenau: EDIFURB, 2001. p. 11-33.

VAZ, Alexandre F. Treinar o corpo, dominar a natureza: notas para uma análise do esporte com base no treinamento corporal. Caderno Cedes, v. 19, n. 48, p.89-108, ago. 1999.

ZANOLLA, Silvia R. S. Indústria cultural e infância: estudo sobre formação de valores em crianças no universo do jogo eletrônico. Educação e Sociedade [online], v. 28, n.101, p.1329-135, 2007. 